\title{
The Effect of $\mathrm{CoQ}_{10}$ Supplementation on Quality of Life in Women with Breast Cancer Undergoing Tamoxifen Therapy: A Double-Blind, Placebo- Controlled, Randomized Clinical Trial
}

This article was published in the following Dove Press journal:

Psychology Research and Behavior Management

\section{Seyed Ahmad Hosseini ${ }^{1}$ \\ Nazanin Zahrooni ${ }^{2}$ \\ Ahmad Ahmadzadeh ${ }^{3}$ \\ Kambiz Ahmadiangali ${ }^{4}$ \\ Mohammad-Ali \\ Assarehzadegan $^{5}$}

'Nutrition and Metabolic Diseases Research Center, Ahvaz Jundishapur University of Medical Sciences, Ahvaz, Iran;

${ }^{2}$ Department of Nutrition, Faculty of Paramedicine, Ahvaz Jundishapur

University of Medical Sciences, Ahvaz, Iran;

${ }^{3}$ Thalassemia and Hemoglobinopathy

Research Center, Ahvaz Jundishapur University of Medical Sciences, Ahvaz, Iran;

${ }^{4}$ Biostatistics Division, Health School, Ahvaz Jundishapur University of Medical Sciences, Ahvaz, Iran; ${ }^{5}$ mmunology Research Center, Institute of Immunology and Infectious Diseases, Iran University of Medical Science, Tehran, Iran
Correspondence: Nazanin Zahrooni Department of Nutrition, Faculty of Paramedicine, Ahvaz Jundishapur University of Medical Sciences, Ahvaz, Iran Tel +98 6I 33367543

Fax $+98-6133720299$

Email nzahroonii@gmail.com
Background: Survival rates among breast cancer patients and the number of patients living with treatment side effects have improved, leading to increased focus on quality of life (QOL). The objective of this study was to determine the efficacy of $\mathrm{CoQ}_{10}$ on QOL scores among breast cancer patients in Iranian undergoing tamoxifen therapy.

Methods: Thirty breast cancer patients were randomized into two groups. The first group received $100 \mathrm{mg} \mathrm{CoQ}{ }_{10}$, and the second group took fplacebo once a day for 8 weeks. QOL was evaluated by a standard QOL questionnaire and a specific questionnaire on QOL of breast cancer patients at baseline and the end of the study. Also, physical activity of patients was assessed with the IPAQ questionnaire and dietary intake determined by a 3-day dietary record.

Results: The data of 30 subjects were analyzed. According to QOL C30 data, $\mathrm{CoQ}_{10}$ led to a significant increase in physical functioning $(P=0.029)$, emotional functioning $(P=0.031)$, and cognitive functioning $(P=0.023)$ compared to placebo. Symptom scales revealed a notable reduction in appetite loss in the first group $(P=0.01)$. Global health status showed no significant changes in either study arm. On the QOL BR23, progress in functions and decline in symptoms were not statistically significant. Arm symptoms showed significant reduction $(P=0.022)$ in patients that received placebo.

Conclusion: This trial indicates that $\mathrm{CoQ}_{10}$ supplementation has effects in ameliorating some dimensions of QOL in breast cancer patients. To generalize the results, larger and longer intervention studies are needed.

Clinical Trial Registration: IRCT2015042021874N1.

Keywords: breast cancer, $\mathrm{CoQ}_{10}$, quality of life, tamoxifen

\section{Background}

Breast cancer is the most common cancer in women in both developed and less developed countries. It is estimated that worldwide, over 627,000 women died in 2018 due to breast cancer. ${ }^{1}$ More than $14 \%$ of mortality causes in women in Iran are related to breast cancer. ${ }^{2}$ Although the incidence rate of breast cancer in Asian countries (such as Iran) is lower than in Western countries, the trend in Iran is rising. ${ }^{3}$ Breast cancer-survival rates differ considerably worldwide, ranging from $80 \%$ or over in North America, Sweden, and Japan to around $60 \%$ in middle-income countries and $<40 \%$ in low-income countries. ${ }^{4}$

With regard to cancer, survival rate is considered one of the main prognostic indicators of the disease. In addition to various demographic factors, this index is 
influenced by the stage of cancer when diagnosed and the type of treatment, or in other words, diagnostic and therapeutic measures. ${ }^{5,6}$ Studies conducted in Iran's provinces over the past decade have estimated the 5-year survival rate in breast cancer patients to be $48 \%-87 \%$. $^{7}$ These differences may be due to patients' biological, racial/ genetic, geographical, socioeconomic, and cultural differences, and also different treatment options and patients' access to these facilities.

The World Health Organization defines health as "a state of complete physical, mental, and social well-being, not merely the absence of disease or infirmity". Therefore, this is necessary to comprise an estimation of well-being, evaluated by quantifying advances in quality of life (QOL) related to health care, in addition to changes in the frequency and severity of diseases by measuring health and health-care consequences. ${ }^{8}$ Researchers have proposed that at least $80 \%$ of cancer patients, particularly those undergoing multiple treatments, experience notable levels of fatigue that may negatively affect their QOL, emotional well-being, and treatment tolerance. ${ }^{9}$ Some practical techniques for breast cancer patients' treatment are mastectomy, radiotherapy, and chemotherapy plus hormonal therapy. Although these effective treatment methods lead to increased survival rates in breast cancer patients, the QOL of such patients is fluctuating and often poor. ${ }^{10,11}$ For example, long-term radiotherapy or chemotherapy often results in loss of self-confidence, substantial disruption in physical functioning, mental health, and wellbeing, and impaired QOL. In addition, total or partial mastectomy could be one of the reasons of psychological and emotional problems such as depression and anxiety, all affect QOL of breast cancer patients. ${ }^{12,13}$

$\mathrm{CoQ}_{10}$ is a lipophilic inner mitochondrial membrane cofactor with ten isoprenoid units that shuttle electrons in the formation of ATP, with wide distribution in the human body. ${ }^{14}$ Decreased critical levels of $\mathrm{CoQ}_{10}$ result in the reduction of energy production and antioxidant-protection capacity in cancer patients, due to two factors: cancer is more prevalent in older persons and $\mathrm{CoQ}_{10}$ synthesis declines with aging; and older cancer patients have multiple complications, such as oxidative stress, chemo/radiotherapy, and anticancer-drug usage, which lead to reductions in $\mathrm{CoQ}_{10}$ levels. ${ }^{15}$

Studies on the effectiveness of $\mathrm{CoQ}_{10}$ on QOL in different diseases have indicated that this supplement can have a beneficial effect on QOL. ${ }^{16-18}$ However, there have been few studies on breast cancer, ${ }^{9}$ and to our knowledge, a trial evaluating the effect of $\mathrm{CoQ}_{10}$ alone in breast cancer patients has not been done yet. Considering the high prevalence of breast cancer, in addition to its importance and effects on all life dimensions of patients, focusing on QOL as it relates to health and finding solutions to ameliorate QOL of these patients seems necessary. Therefore, we aimed to determine the efficacy of $\mathrm{CoQ}_{10}$ on QOL scores that had been collected in a double-blind randomized clinical trial for Iranian women with breast cancer.

\section{Methods}

\section{Patients}

The target population of this randomized double-blind placebo-controlled clinical trial was women diagnosed as breast cancer patients with positive estrogen receptor by their physicians. Patients entered the study from the Medical Oncology Department of the Governmental Shaffa Hospital, Ahvaz, Iran after meeting the inclusion criteria: age 19-49 years, at least 6 months since chemotherapy and radiation therapy, a history of taking 20 $\mathrm{mg}$ /day tamoxifen for at least 1 year, not taking $\mathrm{CoQ}_{10}$ supplements or other antioxidants, such as vitamin E, willingness to comply with all interventions and follow-up procedures, not pregnant or lactating, having no uncontrolled diseases, such as diabetes and thyroid disorders, and not taking nonprescription drugs, corticosteroids, or statins. Exclusion criteria comprised metastasis and total or partial mastectomy. There was no menstrual cycle in the patient/placebo group $(14,93.3 \%)$ or the patient $/ \mathrm{CoQ}_{10}$ group $(14,93.3 \%)$ with the exception of one person in each group with regular menstrual cycles. All patients were at stage 1 or 2 breast cancer. Informed consent was received from all subjects after explanation of the study.

A total of 143 women diagnosed as breast cancer patients with positive estrogen receptor were assessed for eligibility, and 30 patients met the inclusion criteria. Subjects were divided into two groups using simple random sampling: 15 breast cancer patients received $100 \mathrm{mg} /$ day $\mathrm{CoQ}_{10}$ orally (group $\mathrm{A}$ ), and 15 breast cancer patients took $100 \mathrm{mg} /$ day placebo (wheat flour encapsulated similarly in shape and color to the desired supplement, group B) for 2 months. For better absorption of supplements, subjects were advised to take them within meals, and compliance was calculated by counting the number of tablets given to each subject and recollected at the end of the trial. All procedures were performed at the Medical Oncology Department of Shaffa Hospital by the researchers, and patients were followed up by phone call weekly. 


\section{Assessment of Dietary Intake}

A validated questionnaire and 3-day dietary record, including two weekdays and one weekend day, under supervision of a dietitian were completed by all subjects before and after the end of the study period. Dietary energy and nutrient intake were analyzed by Nutritionist IV software. Soy and soy products use were forbidden, because of estrogen-agonistic/antagonistic effects. ${ }^{19}$

\section{Assessment of Quality of Life}

The QOL of patients was evaluated using a standard QOL questionnaire (C30) and a specific questionnaire on QOL of breast cancer patients (BR23). The European Organisation for Research and Treatment of Cancer (EORTC) QLQ-C30 encompasses 30 items, including five functional scales (physical, role, emotional, cognitive, and social) and nine symptom scales (fatigue, nausea and vomiting, pain, dyspnoea, insomnia, appetite loss, constipation, diarrhea, financial difficulties) plus one global health scale. The BR23 questionnaire consists of 23 questions designed to quantify QOL in breast cancer, including five functional scales (body image, sexual functioning, sexual enjoyment, future perspectives), and four symptom scales (systematic therapy side effects, breast symptom, arm symptoms, upset about hair loss). ${ }^{20}$

The EORTC QLQ was translated into Persian and validated by Safaee et $\mathrm{al}^{21}$ and Montazeri et al. ${ }^{22}$ In general, the findings of these studies indicated that the Iranian version of the EORTC QLQ-C30 and QLQ-BR23 were reliable and valid measures of QOL in breast cancer patients and can be used in clinical trials and studies of outcome research in oncology. After information collection from patients by QOL questionnaires, raw scores for each subscale were calculated and then changed to $0-100$ scales according to the guidelines of the EORTC scoring manual. Higher scores on functioning scales and global health status indicate better QOL or a high level of functioning. In the case of symptom scales, higher scores indicate the higher levels of symptoms, a critical indicator of QOL. ${ }^{9}$ Physical activity was assessed by the International Physical Activity Questionnaire, ${ }^{23}$ which asks subjects about their physical activity in five sections: job-related, transportation, housework, recreation, and time spent sitting). In order to analyze this questionnaire, the relevant guidelines were used. ${ }^{24}$

\section{Sample Size}

According to Premkumar et al, using Minitab software with $95 \%$ CI and test power of $90 \%$, the sample size in each group was set at ten. To increase the accuracy of the study and to prevent a $50 \%$ drop, the sample size was increased to 15 individuals.

\section{Statistical Analysis}

Data were analyzed with SPSS version 22. The ShapiroWilk test was used to specify the normality of the variables' distribution. The multi-item scales of EORTC QLQ-C30 and all subscales of BR23 were analyzed for relationships. ANCOVA and least significant-difference tests were applied to determine associations between study groups and independent/dependent variables measured before and after the trial. Dietary energy and nutrient intake were analyzed with Nutritionist IV. Values are presented as means \pm SD, with significance set at $P<0.05$.

\section{Results}

Thirty patients $\left(15 \mathrm{CoQ}_{10}\right.$ and 15 Placebo) completed the study. Some subject characteristics at the beginning of the study (Table 1) were not significantly different between placebo and $\mathrm{CoQ}_{10}$ groups. Dietary intake of energy and macronutrients was assessed and showed no differences between groups at baseline and had not changed at the end of 2 months (Table 2). Research has revealed that physical activity may affect $\mathrm{CoQ}_{10}$ plasma levels, ${ }^{25}$ and thus this was determined using the International Physical Activity Questionnaire (Table 3). No significant difference was observed between groups.

Tables 4 and 5 shows the effect of $\mathrm{CoQ}_{10}$ on QOL components during the two phases of measurement and their changes during the study. According to QOL C30 data, analysis of the questionnaires showed that supplementation with $\mathrm{CoQ}_{10}$ significantly increased physical functioning $(P=0.029)$ compared to placebo. Also, emotional functioning and cognitive functioning of patients after supplementation significantly increased $(P=0.031$ and $P=0.023$, respectively). An insignificant increasing trend was observed on other functional scales, indicating better QOL than at the beginning of the study. Symptom scales revealed a notable reduction in appetite loss in the $\mathrm{CoQ}_{10}$ group $(P=0.01)$. Global health status showed no significant changes in the $\mathrm{CoQ}_{10}$ or placebo arm. In the case of symptom scales, insignificant decreases were found in fatigue, nausea and vomiting, pain, insomnia, and constipation. However, financial problems increased significantly in the intervention group $(P<0.0001)$. On the QOL BR23, progress on functional scales (body image, sexual functioning, sexual enjoyment, and future perspectives) and decline on symptom scales 
Table I Anthropometric and Demographic Characteristics in Breast Cancer Patients in the Study

\begin{tabular}{|c|c|c|c|}
\hline \multirow[t]{2}{*}{ Variables } & Placebo & $\mathrm{CoQ}_{10}$ & \multirow[t]{2}{*}{$P$-value } \\
\hline & $n=15$ & $n=15$ & \\
\hline Age (years) & $36.33 \pm 7.73$ & $40.66 \pm 5.19$ & 0.108 \\
\hline Height (cm) & $158.26 \pm 2.40$ & $158.53 \pm 6.02$ & 0.969 \\
\hline Weight (kg) & $64.33 \pm 8.46$ & $65.26 \pm 8.43$ & 0.901 \\
\hline $\begin{array}{l}\text { Body-mass index } \\
(\mathrm{kg} \cdot \mathrm{m}-2)\end{array}$ & $25.66 \pm 3.15$ & $25.96 \pm 3.01$ & $0.250 *$ \\
\hline $\begin{array}{l}\text { Educational } \\
\text { Illiterate } \\
\text { Primary } \\
\text { Secondary } \\
\text { College/university }\end{array}$ & $\begin{array}{l}2(13.3 \%) \\
\text { II (73.3\%) } \\
\text { I }(6.7 \%) \\
\text { I }(6.7 \%)\end{array}$ & $\begin{array}{l}6(40 \%) \\
7(46.7 \%) \\
\text { I }(6.7 \%) \\
I(6.7 \%)\end{array}$ & 0.689 \\
\hline $\begin{array}{l}\text { Marital status } \\
\text { Married } \\
\text { Unmarried }\end{array}$ & $\begin{array}{l}\text { I4 (93.3\%) } \\
\text { I (6.7\%) }\end{array}$ & $\begin{array}{l}13(86.7 \%) \\
2(13.3 \%)\end{array}$ & 0.857 \\
\hline $\begin{array}{l}\text { Cigarette/alcohol } \\
\text { No } \\
\text { Yes }\end{array}$ & $\begin{array}{l}\text { I4 (93.3\%) } \\
\text { I (6.7\%) }\end{array}$ & $\begin{array}{l}\text { I4 (93.3\%) } \\
\text { I (6.7\%) }\end{array}$ & I \\
\hline $\begin{array}{l}\text { Physical activity } \\
\text { Light } \\
\text { Moderate } \\
\text { Vigorous }\end{array}$ & $\begin{array}{l}15(100 \%) \\
0 \\
0\end{array}$ & $\begin{array}{l}\text { I4 (93.3\%) } \\
\text { I (6.7\%) } \\
0\end{array}$ & I \\
\hline
\end{tabular}

Notes: Anthropometric data given as mean \pm SD and demographic data as $n$ (\%). Kruskal-Wallis test used for age, height, and weight, and $\chi^{2}$ used for other variables. *Difference between treatment and placebo groups at follow-up and baseline visits using ANCOVA. (systemic therapy side effects, breast symptoms, and upset with hair loss) were not statistically significant. Arm symptoms (BRAS) showed significant reduction $(P=0.022)$ in subjects receiving placebo.

\section{Discussion}

Cancer treatments, such as chemotherapy, in breast cancer patients can cause several side effects and symptoms, including physical, functional, psychological and social difficulties (anxiety, depression, pain, fatigue, and arm morbidity), that affect QOL. Clinical trials have demonstrated that evaluation of QOL and making changes leads to treatment improvement, increasing survival in cancer patients. ${ }^{26}$ It has been shown that numerous disease processes associated with $\mathrm{CoQ}_{10}$ deficiency can benefit from $\mathrm{CoQ}_{10}$ supplementation, including cancer. In this study, we evaluated the efficacy of $\mathrm{CoQ}_{10}$ on QOL in breast cancer patients. ${ }^{27}$

The results of this study demonstrated that oral $\mathrm{CoQ}_{10}$ supplementation (100 mg/day) for 8 weeks had beneficial effects on physical, emotional, and cognitive functioning, as well as appetite. However, global health status remained unchanged after $\mathrm{CoQ}_{10}$ supplementation. Furthermore, there was a not-inconsiderable improvement in other dimensions of EORTC questionnaire scores in the supplemented group that showed nonstatistically significant but clinical importance of $\mathrm{CoQ}_{10}$ in ameliorating QOL. These outcomes were obtained despite the low sample size and short study duration, and for better understanding of

Table 2 Dietary Intake of Energy and Macronutrients in Breast Cancer Patients in the Study

\begin{tabular}{|c|c|c|c|}
\hline \multirow[t]{2}{*}{ Variables } & \multirow{2}{*}{$\begin{array}{l}\text { Before } \\
\text { Mean } \pm \text { SD }\end{array}$} & \multirow{2}{*}{$\begin{array}{l}\text { After } \\
\text { Mean } \pm \text { SD }\end{array}$} & \multirow[t]{2}{*}{ P-value* } \\
\hline & & & \\
\hline Energy (kcal) & & & 0.946 \\
\hline Patient/placebo & $2,044.46 \pm 355.90$ & $2,058.46 \pm 341.95$ & \\
\hline Patient/CoQ10 & $2,026.93 \pm 351.12$ & $2,034.33 \pm 354.05$ & \\
\hline Protein (g) & & & 0.192 \\
\hline Patient/placebo & $60.65 \pm 10 \pm 66$ & $61.65 \pm 10.85$ & \\
\hline Patient/CoQ 10 & $45.74 \pm 8.58$ & $49.04 \pm 10.16$ & \\
\hline Carbohydrates (g) & & & 0.121 \\
\hline Patient/placebo & $279.70 \pm 46.52$ & $282.24 \pm 48.86$ & \\
\hline Patient/CoQ 10 & $296.77 \pm 54.23$ & $296.60 \pm 51.60$ & \\
\hline Fat (g) & & & 0.111 \\
\hline Patient/placebo & $74.69 \pm 14.39$ & $74.47 \pm 13.19$ & \\
\hline Patient/CoQ 10 & $73.01 \pm 14.45$ & $75.16 \pm 15.57$ & \\
\hline
\end{tabular}

Notes: *Difference between treatment and placebo groups at follow-up and baseline visits using ANCOVA. 
Table 3 Physical Activity Levels of Breast Cancer Patients at Baseline and End Point of Study

\begin{tabular}{|c|c|c|c|c|}
\hline \multirow{2}{*}{\multicolumn{2}{|c|}{ Variables }} & \multirow{2}{*}{$\begin{array}{l}\text { Before } \\
\text { (Mean } \pm \text { SD) }\end{array}$} & \multirow{2}{*}{$\begin{array}{l}\text { After } \\
\text { (Mean } \pm \text { SD) }\end{array}$} & \multirow[t]{2}{*}{$P$-value } \\
\hline & & & & \\
\hline Work domain & $\begin{array}{l}\text { Walking, MET-minutes/week at work } \\
\text { Patient/placebo } \\
\text { Patient/CoQ } 10 \\
\text { Moderate MET-minutes/week at work } \\
\text { Patient/placebo } \\
\text { Patient/CoQ } \\
\text { Vigorous MET-minutes/week at work } \\
\text { Patient/placebo } \\
\text { Patient/CoQ } 10 \\
\text { Total work, MET-minutes/week } \\
\text { Patient/placebo } \\
\text { Patient/CoQ } 10\end{array}$ & $\begin{array}{l}92.40 \pm 243.84 \\
195.80 \pm 458.36 \\
192 \pm 506.68 \\
474.66 \pm 1541.04 \\
896 \pm 2364.53 \\
56 \pm 216.88 \\
1,180.40 \pm 3115.06 \\
726.46 \pm 1927.19\end{array}$ & $\begin{array}{l}215.60 \pm 450.55 \\
46.20 \pm 178.93 \\
856 \pm 2268.17 \\
250.66 \pm 863.14 \\
1,133.33 \pm 4,334.20 \\
37.33 \pm 144.59 \\
2,204.93 \pm 679.48 \\
334.20 \pm 9 \mid 2.93\end{array}$ & $\begin{array}{l}0.234 \\
0.288 \\
0.958 \\
0.541\end{array}$ \\
\hline $\begin{array}{l}\text { Active transportation } \\
\text { domain* }\end{array}$ & $\begin{array}{l}\text { Walking, MET-minutes/week for transport } \\
\text { Patient/placebo } \\
\text { Patient/CoQ } 10 \\
\text { Total transport, MET-minutes/week } \\
\text { Patient/placebo } \\
\text { Patient/CoQ } 10\end{array}$ & $\begin{array}{l}272.80 \pm 211.47 \\
600.60 \pm 758.22 \\
272.80 \pm 211.47 \\
600.60 \pm 758.22\end{array}$ & $\begin{array}{l}595.10 \pm 1204.16 \\
262.90 \pm 240.44 \\
595.10 \pm 1204.16 \\
262.90 \pm 240.44\end{array}$ & $\begin{array}{l}0.305 \\
0.305\end{array}$ \\
\hline $\begin{array}{l}\text { Domestic and garden } \\
\text { (yard work) domain }\end{array}$ & $\begin{array}{l}\text { Vigorous MET-minutes/week yard chores } \\
\text { Patient/placebo } \\
\text { Patient/CoQ } 10 \\
\text { Moderate MET-minutes/week yard chores } \\
\text { Patient/placebo } \\
\text { Patient/CoQ } 10 \\
\text { Moderate MET-minutes/week inside chores } \\
\text { Patient/placebo } \\
\text { Patient/CoQ } \\
\text { Total domestic and garden moderate MET-minutes/week } \\
\text { Patient/placebo } \\
\text { Patient/CoQ } 10\end{array}$ & $\begin{array}{l}641.66 \pm 1616.08 \\
34.83 \pm 55.45 \\
600 \pm 1125.39 \\
209.33 \pm 187.13 \\
793 \pm 774.72 \\
658 \pm 664.77 \\
2,034.66 \pm 3461.93 \\
902.16 \pm 807.45\end{array}$ & $\begin{array}{l}170.50 \pm 257.80 \\
60.50 \pm 149.97 \\
380 \pm 277.23 \\
220 \pm 168.69 \\
552 \pm 450.54 \\
744 \pm 437.13 \\
1,102.50 \pm 884.95 \\
1,024.50 \pm 604.86\end{array}$ & $\begin{array}{l}0.758 \\
0.846 \\
0.060 \\
0.160\end{array}$ \\
\hline Leisure-time domain & $\begin{array}{l}\text { Walking MET-minutes/week leisure } \\
\text { Patient/placebo } \\
\text { Patient/CoQ } 10 \\
\text { Moderate MET-minutes/week leisure } \\
\text { Patient/placebo } \\
\text { Patient/CoQ } 10 \\
\text { Vigorous MET-minutes/week leisure } \\
\text { Patient/placebo } \\
\text { Patient/CoQ } 10 \\
\text { Total leisure-time MET-minutes/week } \\
\text { Patient/placebo } \\
\text { Patient/CoQ } 10\end{array}$ & $\begin{array}{l}376.20 \pm 427.69 \\
227.70 \pm 234.52 \\
93.3 \pm 170.82 \\
10.66 \pm 28.14 \\
56 \pm 149.51 \\
352 \pm 967.96 \\
525.53 \pm 593.27 \\
590.36 \pm 1038.92\end{array}$ & $\begin{array}{l}3|1.30 \pm 194.5| \\
267.30 \pm 269.62 \\
37.33 \pm 83.44 \\
140 \pm 300.57 \\
85.33 \pm 155.55 \\
320 \pm 877.91 \\
433.96 \pm 255.81 \\
727.30 \pm 1068.82\end{array}$ & $\begin{array}{l}0.190 \\
0.159 \\
0.549 \\
0.249\end{array}$ \\
\hline Sitting domain & $\begin{array}{l}\text { Sitting, total minutes/week } \\
\text { Patient/placebo } \\
\text { Patient/CoQ } 10 \\
\text { Average sitting total minutes/day } \\
\text { Patient/Placebo } \\
\text { Patient/CoQ } 10\end{array}$ & $\begin{array}{l}1,457.33 \pm 1,180.59 \\
1,988 \pm 1,005.74 \\
208.19 \pm 168.65 \\
284 \pm 143.67\end{array}$ & $\begin{array}{l}I, 541.53 \pm 1,127.93 \\
I, 776 \pm 826.66 \\
220.21 \pm|6| .13 \\
253.7| \pm| 18.09\end{array}$ & $\begin{array}{l}0.060 \\
0.060\end{array}$ \\
\hline
\end{tabular}

Notes: $P$-values for difference between treatment and placebo groups at follow-up and baseline visits using ANCOVA. Metabolic equivalent: I MET = I kcal/kg/hour). $* T h i s$ section includes two areas of walking and cycling. Due to the negative response to participation in cycling, this area was removed in the data analysis. 
Table 4 Effect of Coenzyme $Q_{10}$ Supplementation on QOL C30 in Breast Cancer Patients

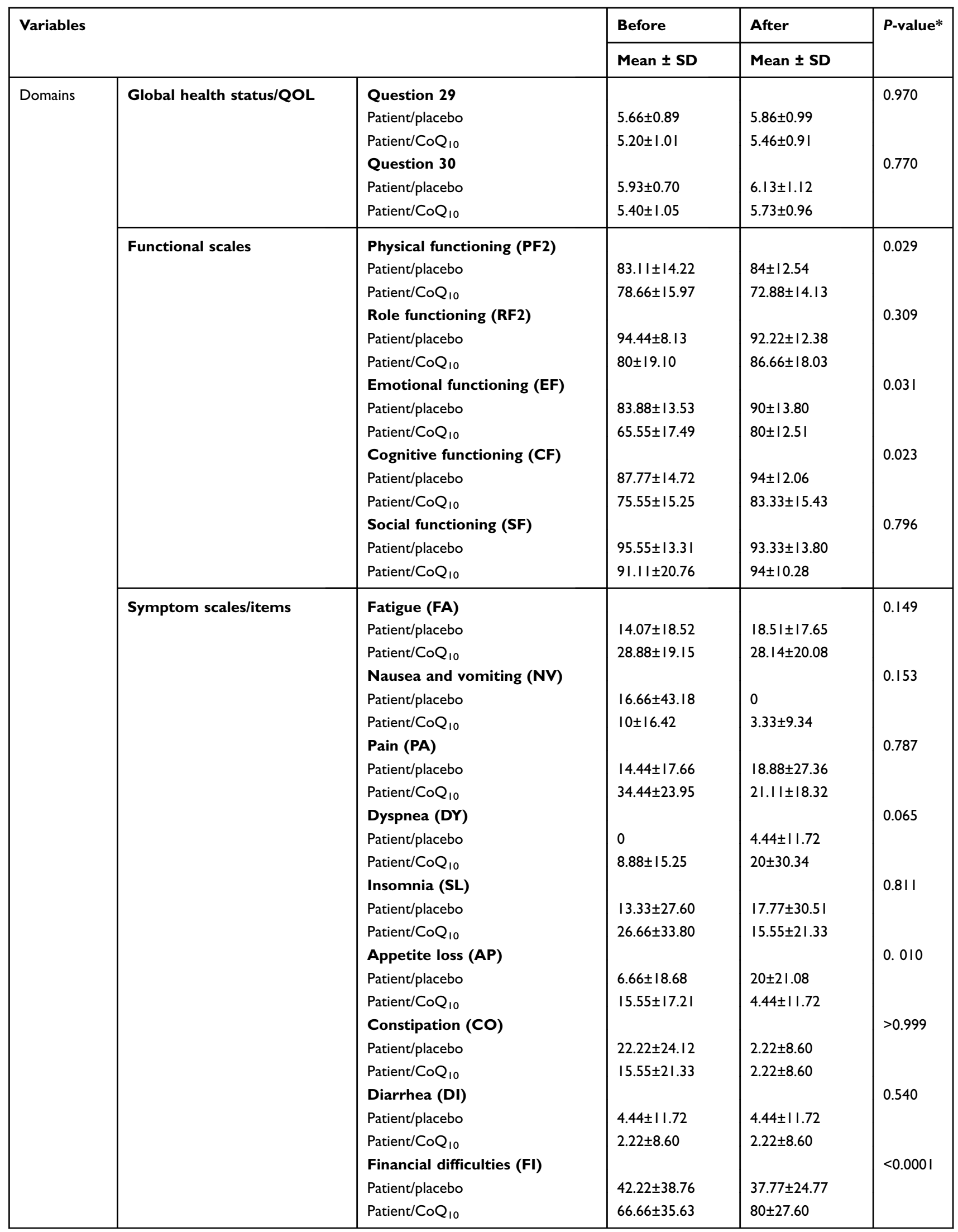

Notes: *Difference between treatment and placebo groups at follow-up and baseline visits using ANCOVA. P<0.05 significant. 
Table 5 Effect of Coenzyme $Q_{10}$ Supplementation on QOL Br23 in Breast Cancer Patients

\begin{tabular}{|c|c|c|c|c|c|}
\hline \multicolumn{3}{|c|}{ Variables } & \multirow{2}{*}{$\begin{array}{l}\text { Before } \\
\text { Mean } \pm \text { SD }\end{array}$} & \multirow{2}{*}{$\frac{\text { After }}{\text { Mean } \pm \text { SD }}$} & \multirow[t]{2}{*}{ P-value* } \\
\hline & & & & & \\
\hline \multirow[t]{2}{*}{ Domains } & Functional scales & $\begin{array}{l}\text { Body image (BRBI) } \\
\text { Patient/placebo } \\
\text { Patient/CoQ } 10 \\
\text { Sexual functioning (BRSEF) } \\
\text { Patient/placebo } \\
\text { Patient/CoQ } 10 \\
\text { Sexual enjoyment (BRSEE) } \\
\text { Patient/placebo } \\
\text { Patient/CoQ } 10 \\
\text { Future perspective (BRFU) } \\
\text { Patient/placebo } \\
\text { Patient/CoQ }\end{array}$ & $\begin{array}{l}76.66 \pm 22.31 \\
65 \pm 20.70 \\
32.22 \pm 7.62 \\
27.38 \pm 19.17 \\
44.44 \pm 20.57 \\
23.80 \pm 24.20 \\
57.77 \pm 38.76 \\
62.22 \pm 27.79\end{array}$ & $\begin{array}{l}71.11 \pm 27.43 \\
70.55 \pm 20.86 \\
72.22 \pm 13.60 \\
71.79 \pm 23.94 \\
22.22 \pm 24.12 \\
30.95 \pm 27.62 \\
55.55 \pm 34.88 \\
68.88 \pm 19.78\end{array}$ & $\begin{array}{l}0.948 \\
0.951 \\
0.347 \\
0.183\end{array}$ \\
\hline & Symptom scales/items & 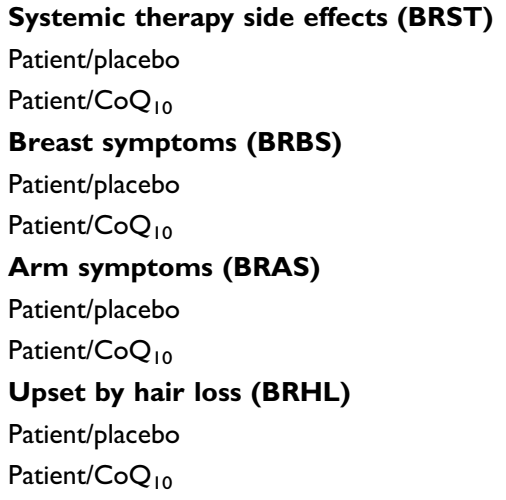 & $\begin{array}{l}20.31 \pm 21.85 \\
27.61 \pm 10.21 \\
13.33 \pm 17.19 \\
8.33 \pm 7.7 \mid \\
20 \pm \mid 8.87 \\
18.874 \pm \mid 8.24 \\
|1.11 \pm 27.2| \\
8.88 \pm 15.25\end{array}$ & $\begin{array}{l}18.73 \pm 17.76 \\
24.12 \pm 12.53 \\
13.33 \pm 21.77 \\
10.55 \pm \mid 1.55 \\
14.8 \mid \pm 20.85 \\
34.07 \pm 26.38 \\
15.55 \pm 35.33 \\
4.44 \pm 11.72\end{array}$ & $\begin{array}{l}0.320 \\
0.651 \\
0.022 \\
0.232\end{array}$ \\
\hline
\end{tabular}

Notes: *Difference between treatment and placebo groups at follow-up and baseline visits using ANCOVA. $P<0.05$ is significant.

$\mathrm{CoQ}_{10}$ effects on QOL of breast cancer patients, more clinical trials are needed.

Although the effects of $\mathrm{CoQ}_{10}$ on QOL among patients with other chronic diseases have been studied in several clinical trials with conflicting results, to our knowledge this is the first study indicating the effect of $\mathrm{CoQ}_{10}$ supplementation alone on QOL in patients with breast cancer. There have been some clinical trials done to assess the effect of $\mathrm{CoQ}_{10}$ supplementation alone on QOL in breast cancer patients, and the their results were in line with our study.

Guilbot et al suggested that 12 weeks of a combination of feverfew, magnesium, and $\mathrm{CoQ}_{10}$ at a dosage of 100 $\mathrm{mg} /$ day for migraine prophylaxis significantly reduced the number of days with migraine headache and improved QOL. ${ }^{16}$ In another study, Sharifi et al showed that both a therapeutic lifestyle-change diet and supplementation with $\mathrm{CoQ}_{10}(150 \mathrm{mg} /$ day $)$ and L-carnitine had a positive effect on the physical and emotional subscales of the MacNew questionnaire in patients with myocardial infarction. ${ }^{17}$ In addition, Morris et al illustrated the $\mathrm{CoQ}_{10}$ 's potential role in improving QOL in patients with Parkinson's disease and fibromyalgia. Also, it showed antidepressive effects and significantly reduced fatigue and improved ergonomic performance during exercise. ${ }^{28}$ Other studies assessing the effect of $\mathrm{CoQ}_{10}$ in combination with other nutrients, such as $\mathrm{NADH}$, in chronic fatigue syndrome ${ }^{29}$ and high-dose micronutrients in patients with chronic heart failure ${ }^{18}$ have indicated significant improvement in QOL and other dimensions of health care.

In contrast to our study, clinical trials have revealed conflicting results, eg, $300 \mathrm{mg} /$ day $\mathrm{CoQ}_{10}$ or placebo, each combined with $300 \mathrm{IU}$ vitamin $\mathrm{E}$, divided into three daily doses for 24 weeks led to increase in plasma $\mathrm{CoQ}_{10}$ levels, but did not result in improved self-reported fatigue or QOL in breast cancer patients. ${ }^{9}$ Also, a study on amino-acid jelly containing $\mathrm{CoQ}_{10}$ and L-carnitine in controlling fatigue in breast cancer patients receiving chemotherapy showed that EORTC QLQ-C30, and EORTC QLQ-BR23 scores were not significantly different between the two groups. ${ }^{30}$ Muscle strength, muscle endurance, and QOL increased statistically 
significantly in all postpolio-syndrome patients in both groups of $\mathrm{CoQ}_{10}$ supplementation and placebo, which revealed $\mathrm{CoQ}_{10}$ had no beneficial effect. ${ }^{31}$

Multiple roles as an antioxidant, a membrane stabilizer, and specifically mitochondria regulation, which optimize cellenergy generation, are some aspects of cellular $\mathrm{CoQ}_{10}$ functioning. Lowered $\mathrm{CoQ}_{10}$ levels are connected with high inflammation, oxidative/nitrosative stress, and dysfunction of mitochondria, which are activated by intracellular signaling pathways, including NFאB, MAPK, and JAK-STAT. As such, proteins and fatty acids in cell membranes can be attacked by ROS, which reduces membrane fluidity and diminishes the performance of cell-membrane receptors and ion channels, thus disrupting intercellular and intracellular signaling processes and leading to such disorders as fatigue, hyperalgesia, depression, and neurodegenerative processes. ${ }^{27,32,33}$ Also, in depleted levels of $\mathrm{CoQ}_{10}$, uncoupling proteins do not function correctly, which causes inability in regulating cellular fuel metabolism and other ATP-dependent processes. ${ }^{27,34}$ Some genes involved in mitochondrial biogenesis and replication due to increasing energy demands are under $\mathrm{CoQ}_{10}$ control. As a consequence, stimulating oxidative metabolism in response to increased demands for energy could be affected in $\mathrm{CoQ}_{10}$ deficiencys. ${ }^{35} \mathrm{CoQ}_{10}$ treatment decreases fatigue, depression, and hyperalgesia through its anti-inflammatory, antioxidant, and neuroprotective effects. Also, it decreases muscle weakness, increases walking distance, and improves exercise tolerance and oxygen consumption by modification of the performance of complex I of the electron-transfer chain. $^{28}$ Given that, sex and dietary intake are considered confounding factors in QOL. ${ }^{36,37}$ Limiting our sample to women and records of dietary intake are a couple of the strengths of our study.

\section{Conclusion}

In this study, we discovered proof demonstrating significant effects of $\mathrm{CoQ}_{10}$ on physical, social, and mental conditions in women with breast cancer. In short, the supplemented patients showed better QOL at the end of the study. Separate studies should be conducted in different age-groups and larger populations for longer periods to generalize the evidence gained.

\section{Data-Sharing Statement}

The data sets used and/or analyzed during this study are available from the corresponding author on reasonable request. Permission for use was received by the ethics committee of Ahvaz Jundishapur University of Medical Sciences.

\section{Ethics Approval and Consent to Participate}

This clinical protocol was approved by the Research Ethics Committee of the Ahvaz Jundishapur University of Medical Science (protocol number IRAJUMS.REC.1394.246, July 25, 2015) in accordance with the principles of the Declaration of Helsinki. Signed informed consent was obtained from all participants included in the study.

\section{Acknowledgments}

This work is a part of Nazanin Zahrooni's MSc thesis. Special thanks to staff of the Shafa Hematology Clinic Nutrition and Metabolic Disease Research Center, Ahvaz Jundishapur University of Medical Sciences.

\section{Author Contributions}

All authors contributed to data analysis, drafting, and revising the article, gave final approval of the version to be published, and agree to be accountable for all aspects of the work.

\section{Funding}

This study was supported by an intramural grant of the Vice-Chancellor for Research at Ahvaz Jundishapur University of Medical Sciences.

\section{Disclosure}

The authors report no conflicts of interest in this work.

\section{References}

1. Global Health Estimation. WHO. 2013.

2. World Health Organization-Cancer Country Profiles. 2014.

3. Bab S, Abdifard E, Elyasianfar S, Mohammadi P, Heidari M. Time trend analysis of breast cancer in Iran and its six topographical regions: a population-based study. J Med Life. 2019;12(2):140-149. doi:10.25122/jml-2018-0087

4. Coleman MP, Quaresma M, Berrino F, et al. Cancer survival in five continents: a worldwide population-based study (CONCORD). Lancet Oncol. 2008;9:730-756. doi:10.1016/S1470-2045(08)70179-7

5. Ellison LF, Wilkins K. An update on cancer survival. Health Rep. 2010;21:55-60.

6. Compton CC, Byrd DR, Garcia-Aguilar J, Kurtzman SH, Olawaiye A, Washington MK. AJCC Cancer Staging Atlas: A Companion to the Seventh Editions of the AJCC Cancer Staging Manual and Handbook. Springer; 2012:23-31.

7. Rahimzadeh M, Pourhoseingholi MA, Kavehie B. Survival rates for breast cancer in Iranian patients: a meta- analysis. Asian Pac J Cancer Prev. 2016;17(4):2223-2227. doi:10.7314/APJCP.2016.17.4.2223

8. WHOQOL Measuring quality of life. The World Health Organization Quality Of Life Instruments

9. Lesser GJ, Case D, Stark N, et al. Double-blind, placebo-controlled study of oral coenzyme Q10 to relieve self-reported treatment-related fatigue in newly diagnosed patients with breast cancer. $J$ Support Oncol. 2012;11(1):31-42. 
10. Chandrakar N, Shinde RK. Study the early complications of modified radical mastectomy performed. Int Surg J. 2019;6(1):239-243. doi:10.18203/2349-2902.isj20185480

11. Bhandari S, Sriyuktasuth A, Pongthavornkamol K. Treatment-related quality of life in Nepalese women with breast cancer. Asian Pac J Cancer Prev. 2017;18(12):3365-3371. doi:10.22034/APJCP.2017.18. 12.3365

12. Shaikh K, Najmuddin Shabbir M, Ahmed I, Soomro S, Shahzeb Najam M. Frequency of early complications aft er modifi ed radical mastectomy in breast cancer in tertiary care centre. Pak J Surg. 2013;29(1):17-22.

13. Saleha SB, Shakeel A, Shumaila A, Shazia R, Rashid R, Ibrahim M. An assessment of quality of life in breast cancer patients using EORTC QLQ C30. Br23 questionnaire. Iran J Cancer Prev. 2010;3 (2):98-104

14. Yubero D, Allen G, Artuch R, Montero R. The value of coenzyme Q10 determination in mitochondrial patients reprinted from. J Clin Med. 2017;6(37):1-10. doi:10.3390/jcm6040037

15. Mantle D, Hargreaves I. Coenzyme Q10 and degenerative disorders affecting longevity: an overview. Antioxidants. 2019;8(44):1-10. doi:10.3390/antiox 8020044

16. Guilbot A, Bangratz M, Abdellah AS, Lucas CA. Combination of coenzyme Q10, feverfew and magnesium for migraine prophylaxis: a prospective observational study. BMC Complement Altern Med. 2017;17(1):433. doi:10.1186/s12906-017-1933-7

17. Sharifi MH, Eftekhari MH, Ostovan MA, Rezaianazadeh A. Effects of a therapeutic lifestyle change diet and supplementation with Q10 plus L-carnitine on quality of life in patients with myocardial infarction: a randomized clinical trial. J Cardiovasc Thorac Res. 2017;9 (1):21-28. doi:10.15171/jevtr.2017.03

18. Jafari M, Mousavi SM, Asgharzadeh A, Yazdani N. Coenzyme Q10 in the treatment of heart failure: a systematic review of systematic reviews. Indian Heart J. 2018;70(1):S111-S117. doi:10.1016/j.ihj.2018.01.031

19. Kwon Y. Effect of soy isoflavones on the growth of human breast tumors: findings from preclinical studies. Food Sci Nutr. 2014;2 (6):613-622. doi:10.1002/fsn3.2014.2.issue-6

20. Ossein G, Sudabeh V, Masumeh K, Behzad R. Estimation of willingness to pay for mammographic breast cancer screening tests among women in tehran, based on contingent valuation method. Health Manage. 2010;15(47).

21. Saffaie A, Moghimi-Dehkordi B, Tabatabaie SH. Reliability and validity of a specific questionnaire to assess quality of life in cancer patients. Armaghan Danesh J. 1386;12(2):46(persian).

22. Montazeri A, Harirchi I, Vahdani M, et al. The EORTC breast cancerspecific quality of life questionnaire(EORTC-BR23): translation and validation study of the Iranian version. Qual Life Res. 2000;9(2):177184. doi:10.1023/A:1008918310251

23. International Physical Activity Questionnaire. Long last 7 days selfadministered format. 2002.
24. Guidelines for Data Processing and Analysis of the International Physical Activity Questionnaire (IPAQ) - Short and Long Forms. 2005

25. Del Pozo-Cruz J, Rodriguez-Bies E, Ballesteros-Simarro M, et al. Physical activity affects plasma coenzyme Q10 levels differently in young and old humans. Biogerontology. 2014;15(2):199-211. doi:10.1007/s10522-013-9491-y

26. Rahou BH, El Rhazi K, Ouasmani F, et al. Quality of life in Arab women with breast cancer: a review of the literature. Health Qual Life Outcomes. 2016;14(64):1-13. doi:10.1186/s12955-015-0404-4

27. Garrido-Maraver J, Cordero MD, Oropesa-Ávila M, et al. Coenzyme Q 10 therapy. Mol Syndromol. 2014;5:187-197. doi:10.1159/000360101

28. Morris G, Anderson G, Berk M, Maes M. Coenzyme Q10 depletion in medical and neuropsychiatric disorders: potential repercussions and therapeutic implications. Mol Neurobiol. 2013;48(3):833-903.

29. Castro-Marrero J, Cordero MD, Segundo M, et al. Does oral coenzyme Q10 plus NADH supplementation improve fatigue and biochemical parameters in chronic fatigue syndrome? Antioxid Redox Signal. 2015;22(8). doi:10.1089/ars.2014.6181

30. Iwase S, Kawaguchi T, Yotsumoto D, et al. Efficacy and safety of an amino acid jelly containing coenzyme Q10 and L-carnitine in controlling fatigue in breast cancer patients receiving chemotherapy: a multi-institutional, randomized, exploratory trial (JORTC-CAM01). support Care Cancer. 2016;24(2):637-646. doi:10.1007/s00520-0152824-4

31. Skough K, Krossen C, Heiwe S, Theorell H, Borg K. Effects of resistance training in combination with coenzyme Q10 supplementation in patients with post-polio: a pilot study. J Rehabil Med. 2008;40 (9):773-775. doi:10.2340/16501977-0245

32. Anderson G, Maes M. Coenzyme Q10 Depletion: Role in Depression and Depression-Associated Disorders. E-book; 2015.

33. Zhai J, Bo Y, Lu Y, Liu C, Zhang L, López Lluch G. Effects of coenzyme Q10 on markers of inflammation: a systematic review and meta-analysis. PLoS One. 2017;12(1):e0170172. doi:10.1371/journal. pone. 0170172

34. Rodick TC, Seibels DR, Ramesh Babu J, Huggins KW, Ren G, Mathews ST. Potential role of coenzyme Q10 in health and disease conditions. Nutr Diet Suppl. 2018;10:1-11. doi:10.2147/NDS.S112119

35. Donnino MW, Cocchi MN, Salciccioli JD, et al. coenzyme Q10 levels are low and may be associated with the inflammatory cascade in septic shock. Crit Care. 2011;15(4):R189. doi:10.1186/cc10343

36. Choghakhori R, Abbasnezhad A, Amani R, Alipour M. Sex-related differences in clinical symptoms, quality of life, and biochemical factors in irritable bowel syndrome. Dig Dis Sci. 2017;62(6):15501560. doi:10.1007/s10620-017-4554-6

37. Abbasnezhad A, Amani R, Hasanvand A, et al. Association of serum vitamin D concentration with clinical symptoms and quality of life in patients with irritable bowel syndrome. J Am Coll Nutr. 2019;38 (4):327-333. doi:10.1080/07315724.2018.1510349
Psychology Research and Behavior Management

\section{Publish your work in this journal}

Psychology Research and Behavior Management is an international, peer-reviewed, open access journal focusing on the science of psychology and its application in behavior management to develop improved outcomes in the clinical, educational, sports and business arenas. Specific topics covered in the journal include: Neuroscience, memory and decision making; Behavior modification and management; Clinica applications; Business and sports performance management; Social and developmental studies; Animal studies. The manuscript management system is completely online and includes a very quick and fair peer-review system, which is all easy to use. Visit http://www. dovepress.com/testimonials.php to read real quotes from published authors. 